\title{
La naturaleza del Diccionario (A propósito de la Teoría del diccionario monolingüe, de Luis Fernando Lara')
}

\author{
Carmen Castillo Peña \\ Universidad de Padua
}

0. El principio básico que ordena el planteamiento del libro que da lugar a estas notas está ya presente en su título: Teoría del diccionario monolingüe. Su autor, el conocido lexicógrafo mejicano, director del Centro de Estudios Lingüísticos y Literarios del Colegio de México, y del equipo que desde 1973 prepara el Diccionario del español de Méxi$c O^{2}$ explica ya en el "Prólogo" la diferencia entre una teoría del diccionario y un manual de lexicografía. La primera tiene como meta el establecimiento de una hipótesis explicativa sobre la "constitución social" del diccionario, de su "fundamento comunicativo" y de la "concepción del signo lingüístico -el vocablo- que tiene por objeto" (p. 85). La Lexicografía, o metalexicografía -término no grato a Lara- no pasa de ser una técnica incapaz por sí misma de definir la "naturaleza significativa" del diccionario como objeto verbal (p. 16); queda esta, pues, relegada al papel de una especie de manual de instrucciones prácticas, útiles a quienes pretenden elaborar diccionarios o, simplemente, usarlos con fines específicos.

1 L.F. Lara, Teoría del diccionario monolingüe, México, El Colegio de México, 1997, 273 págs.

2 Se han publicado ya el Diccionario fundamental del español de México, México, Fondo de Cultura Económica, 1982; Diccionario básico del español de México, México, El Colegio de México, 1986 y Diccionario del español usual en México, México, El Colegio de México, 1996. 
La perplejidad que puede causar la distinción entre una teoría del diccionario monolingüe y una teoría lexicográfica se resuelve a medida que se prosigue con la lectura. Efectivamente, L. F. Lara (L.) intenta constituir un aparato teórico que explique la legitimidad científica del diccionario como objeto verbal, esto es como producto lingüístico particular, independientemente de la técnica con la que haya sido elaborado y, por tanto, de cualquier perspectiva teórica, editorial, histórica, comercial, descriptiva, etc. Es decir, una teoría que dé cuenta de cualquier diccionario monolingüe sin describirlo en función de sus características externas o internas, ya que "no son los métodos [con los que se elaboran los diccionarios] los que definen la naturaleza significativa de los diccionarios monolingües" (p. 16) ${ }^{3}$.

Si Lexicografía se había convertido en un término demasiado extenso (piénsese en las tan traídas y llevadas diferencias con respecto a la Lexicología, la creación de neologismos como Diccionárica $a^{4}$ y la distinción entre Lexicografía, Metalexicografía, Lexicografía Teórica ${ }^{5}$ o Lexicografía Descriptiva ${ }^{6}$ L. lo aplica a la actividad, al proceso mismo de la elaboración, y a la descripción de sus técnicas, organizando en torno a la Teoría del Diccionario todo el conjunto de reflexiones sobre la naturaleza lingüística de los repertorios lexicográficos monolingües. Como se sabe, estas reflexiones intentan responder fundamentalmente a la cuestión de la relación entre el significado de los signos lingüísticos y las definiciones, y a la relación entre los signos lingüísticos y las entradas o lemas. De aquí surgen necesariamente otros problemas, entre los que sobresale la discutida legitimidad o representatividad normativa del diccionario en una comunidad de hablantes.

3 En Lara 1990, esp. pp. 21-38 se anticipan ya estas ideas.

4 El neologismo es traducción del francés, cfr. Bernard Quemada 1987.

5 Aspectos de Lexicografía teórica, es el título que Ignacio Ahumada Lara da a un estudio sobre la relación entre información semántica e información gramatical en el Diccionario de la RAE. Cfr. Ahumada Lara 1989.

6 Así titula Alvar Ezquerra 1993 su colección de artículos, dedicados a temas tan distintos como, por ejemplo, la descripción de los prólogos de los diccionarios de la Real Academia Española, el Diccionario de Terreros, las relaciones entre Gramática y Diccionario, o los diccionarios bilingües. 
Esta Teoría se propone y desarrolla en siete capítulos: "La construcción simbólica del diccionario" (pp. 21-85), "Pragmática de la información lexicográfica" (pp. 87-112), "El contenido proposicional del acto: la entrada" (pp. 113-129), "El contenido proposicional del acto: la ecuación sémica" (pp. 131-166), "El contenido proposicional del acto: la definición lexicográfica" (pp. 167-231), "La complejidad normativa del diccionario monolingüe" (pp. 233-257) y, finalmente, "Del acto verbal al artículo lexicográfico: conclusión”(pp. 259-263).

1. El primer capítulo es un análisis histórico de la "construcción simbólica" del diccionario. Simbólico porque en su devenir el diccionario se ha convertido, a través de la fijación del vocablo, no solo en el "depósito" de la manifestación fonética, morfológica y sintáctica de una lengua, sino en el árbitro de la normalización de las variantes dialectales y de las valoraciones sociales. En este interesante análisis histórico, el autor sostiene la idea de que el diccionario no nace como respuesta a la necesidad de información, sino como la legitimación política de la lengua hablada por la clase dominante.

1.1. Para ello, se parte de la "idea de la lengua" forjada en el siglo XVI de manera paralela al nacimiento de los estados modernos: la necesidad de fijar la lengua, el concepto de pureza y el de clasicismo confluyen en el origen de los primeros repertorios monolingües: "El diccionario monolingüe comenzó por ser una institución simbólica, un catálogo de voces de la lengua literaria documentadas en un conjunto de obras declaradas clásicas, orientado al esplendor de la lengua del Estado" (p. 33).

Con esta premisa, L. analiza y compara el nacimiento de los grandes diccionarios monolingües de los siglos XVII y XVIII. En Italia, Francia y España se dio pie al nacimiento del concepto de autoridad: la Academia de la Crusca sancionaba la pureza del vocablo porque lo usaban los grandes escritores de los siglos XIV y XV; la Academia francesa se confiere a sí misma la autoridad, confirmada además, por el Estado; la Academia española se abre a la documentación histórica aunando autoridad y uso, erigiéndose "en la documentadora acuciosa del uso que, a 
juicio de los eruditos que la formaban hacía y debía hacer opinión" (p. 44). Las obras de estas instituciones "son más catálogos simbólicos representativos de la calidad del vocabulario literario, restringido por la idea de la lengua imperante, que verdaderas obras de consulta generales. Su simbolismo se dirigía a la legitimación de las lenguas literarias europeas; representaba la lengua como celebración del Estado ante los miembros de la sociedad que participaban en él” (p. 46).

En el mundo anglosajón las cosas, según L., van a ser distintas: el diccionario de Samuel Johnson (1755) fue recibido por la burguesía inglesa como una institución normativa no impuesta por el Estado, sino natural e unánimemente aceptada ante una urgente necesidad de "corrección", distinta, sin embargo, de la pureza aristocrática propia de la idea de la lengua humanista. "Para el público burgués el diccionario se convertía en una obra verdaderamente pedagógica, que ponía a su disposición una lengua correcta" (p. 57). Con la independencia de los Estados Unidos la lengua vuelve a ser un instrumento en manos del Estado, ahora para la salvaguardia de una lengua nacional que sobre la pluralidad de las lenguas maternas de los colonos dé cohesión social al asegurar la comunicación; la ideología democrática e ilustrada estadounidense impidió, como en Inglaterra, la creación de una Academia, pero confirió al diccionario de Noah Webster el mismo papel que al de Johnson habían dado los ingleses.

El impulso que el romanticismo alemán da a la filología abre el camino a los grandes diccionarios históricos, los cuales, a pesar de tener un valor descriptivo que tiende a lo totalizador, no han conseguido borrar el valor normativo que el diccionario común tiene para las sociedades de hablantes; en efecto, tanto los diccionarios históricos como los meramente descriptivos son acogidos por el usuario común con escaso interés, cuando no con feroz crítica. En justa correspondencia, el desarrollo científico de la objetivación lingüística, que dejó de proyectar sobre la lengua valores normativos, ha desdeñado hasta hoy el valor del objeto diccionario.

1.2. Se trata pues de un estudio histórico en el que el prestigio (y su derivado valor normativo) de que se revisten los diccionarios monolin- 
gües no se ve como consecuencia, sino como causa de la existencia de repertorios léxicos propuestos (o impuestos) como modelos a ciertas comunidades lingüísticas. Lo peculiar de este análisis es que se muestra cómo en la creación de los grandes diccionarios monolingües no ha pesado la necesidad de información, sino la de dotar a la lengua de un arma suficientemente eficaz para acompañar al Estado en su tarea de consolidación política.

Con ello se rompe con una concepción en la que se veía el nacimiento del diccionario monolingüe como un producto natural y necesariamente derivado de la tradición bilingüe y, especialmente, de la plurilingüe. Los diccionarios monolingües no derivan, según L., de los plurilingües, (en los que sí hay una evidente motivación práctica), son productos nuevos, hijos de una nueva época.

2. En el segundo capítulo, L. sienta las bases de un análisis pragmático del diccionario; para ello establece unos "postulados de la teoría del lenguaje" y unos "fundamentos de la teoría del significado" (pp. 91-94) gracias a los cuales la lengua, desechando las teorías formalistas que basan todo análisis en la producción, aparece como fundamento del ser social al tener una naturaleza dialógica y no individual. El léxico de una lengua, puente que manifiesta la comprensión del mundo referido, es, a diferencia de la fonética, la morfología y la sintaxis, abierto (se aprende a lo largo de toda la vida del hablante), e ilimitado (trasciende al individuo y a su memoria); por ello su caracterización es necesariamente social (en tanto en cuanto el vocabulario de una lengua es un concepto abstracto que supera las coordenadas espacio temporales del hablante en favor de la comunidad lingüística a la que pertenece). De aquí se sigue la importancia del diccionario como depósito de la memoria social de una lengua; es, pues, uno de los principales instrumentos para el entendimiento de una comunidad lingüística (pp. 87-95).

2.1. Esta función esencial del diccionario es posible porque las preguntas y respuestas acerca del valor de una palabra están pragmáticamente codificadas. Basándose en las teoría de la acción y el acto verbal de Karl Bühler (1967) y John Searle (1980), y en el concepto de la ac- 
ción comunicativa de Jürgen Habermas (1987), L. afirma que la respuesta que se obtiene cuando se pregunta por el significado de un signo es un acto verbal (en el sentido de Searle) socialmente pertinente. Este es el fundamento pragmático del diccionario monolingüe. Además, el diccionario es un producto lingüístico (Bühler) al estar desligado de un emisor concreto, y, por ello, identificado con la sociedad misma.

2.2. Así, si el origen histórico del diccionario es simbólico, su fundamento lingüístico es pragmático: el diccionario es el depósito institucionalizado de los actos verbales sobre el significado del léxico. El artículo lexicográfico adquiere su valor social gracias a:

- La ausencia de marcas que manifiesten el sujeto de la enunciación (es la comunidad misma la que lo emite).

- La condición de sinceridad, por la que el emisor y el receptor creen que el mensaje sobre el significado de una palabra es cierto.

- La condición esencial, por la que se asigna al conocimiento que el emisor tiene sobre la palabra en cuestión un valor universal.

- La presuposición de existencia del significante, del significado y del referente sobre los que versa la pregunta institucionalizada.

La codificación histórica que ha dado forma al artículo lexicográfico es, finalmente, su fuerza ilocucionaria, al ser esta, según Searle, la que indica cuál es el propósito del acto verbal.

Esta caracterización pragmática permite a L. tender un puente entre el origen simbólico (recordemos, no informativo) del diccionario y la función informativa que socialmente cabe asignarle hoy.

2.3. Dos cuestiones surgen de esta interesante propuesta. Una es el desligamiento que implícitamente L. establece entre el diccionario monolingüe y el bilingüe. Parece deducirse que solo el primero es susceptible de este tipo de análisis ya que no se entiende cómo un repertorio bilingüe pueda ser considerado el depósito social del léxico de una lengua. Sin embargo sí sería lícito entender como acto verbal la pregunta sobre el significado de una palabra de "otra" lengua, ya que las con- 
diciones que caracterizan al acto verbal de pregunta "bilingüe" deberían ser necesariamente las mismas (sinceridad, esencialidad, presuposición de existencia, etc.) que las que caracterizan al acto verbal de respuesta "monolingüe". Esto es, el valor atribuido al diccionario monolingüe (memoria institucionalizada del léxico de una lengua) se caracteriza pragmáticamente de una manera de la que también es susceptible el bilingüe. A este respecto, hay, en mi opinión, un aspecto teórico que L. no explica suficientemente, que es, precisamente, el que constituiría la diferencia entre diccionarios bilingües y monolingües. El asunto no me parece trivial por motivos históricos (como decía antes se soslaya la filiación histórica de los últimos respecto de los primeros), y por motivos teóricos. Efectivamente, decidir si se trata de productos verbales distintos o iguales no es indiferente. Si son distintos hay que explicar en qué consisten las diferencias. Si son iguales, hay que aclarar qué papel juegan cada una de las lenguas que intervienen en la organización estructural del artículo lexicográfico. En todo ello cabe además incluir el lugar que se le asignará a los diccionarios de regionalismos o provincialismos, de tanta importancia en la tradición lexicográfica hispánica: ¿Son diccionarios bilingües? o ¿son monolingües?, y en este último caso ¿qué diferencias hay con respecto al monolingüe "general"?.

2.4. La segunda cuestión que me parece interesante mencionar es el hecho de que L., al explicar la naturaleza lingüística del diccionario monolingüe parece estar refiriéndose a un diccionario monolingüe abstracto. ¿Es efectivamente esta la caracterización que merecen todos los diccionarios monolingües? ¿También los de autor? ¿El Diccionario de uso del español de María Moliner representa para sus usuarios lo mismo que el Diccionario de la lengua española de la Real Academia? ¿Son ambos los depositarios de la memoria léxica del español? Aun teniendo las mismas pretensiones de validez $i$ ofrecen las mismas condiciones?

La bien articulada hipótesis de L. consiente aventurar una respuesta para el último grupo de cuestiones: para el hablante común (quizá sería mejor hablar de usuario común), el diccionario, sea cual sea, es el mismo tipo de producto verbal. Lo cual no implica que probablemente hu- 
biese sido conveniente dar cuenta de la multiplicidad de obras que pueden ser llamadas diccionarios monolingües. No olvido que L. comienza su libro advirtiendo que no se trata de un manual de lexicografía, y que su propósito es indagar sobre la naturaleza lingüística del vocabulario, lo cual parece eximirle de una definición previa de qué entiende exactamente por diccionario monolingüe y qué clase de obras son las que se explican, desestimando quizás el riesgo de que el lector identifique imprudentemente $e l$ diccionario monolingüe con un diccionario, como por ejemplo el de la Real Academia Española.

3. En el tercer capítulo L. insiste en la escasa rentabilidad teórica del análisis del artículo lexicográfico como producto metalingüístico, en favor de la explicación pragmática esbozada arriba ${ }^{7}$.

3.1. Para el autor, el proceso de ostentación que implica el aislamiento respecto del discurso de una palabra no es distinto del de cualquier otra objetivación de las entidades del mundo sensible. Así, entre "su marido no me gusta nada" y "su marido no me gusta" no hay más diferencia que la naturaleza del referente atribuible al signo /marido/: extralingüística en el primer caso y lingüística en el segundo. L. argumenta su rechazo a un análisis metalingüístico aduciendo que el efecto teórico inmediato es la duplicación ${ }^{8}$ innecesaria y enojosa del léxico, ya que cada vocablo de lengua tendría un autónimo. Pero la solución que ofrece no deja de ser igualmente compleja: para explicar cómo una unidad del discurso se convierte en lema lexicográfico se ve obligado a distinguir cuatro conceptos: palabra, vocablo, entrada y lema. La primera es la unidad que procede del discurso, del habla en el sentido saussuriano; el vocablo es la forma canónica abstracta producida por la reflexión social sobre la lengua; el lema es la representación lexicográfica del vocablo más las indicaciones morfológicas, sintácticas o fonéticas; por fin, la entrada es la unidad de recuperación de información lexicográfica:

7 El autor ya se ha manifestado en este sentido en varias ocasiones, cfr. Lara 1989 y 1990 , p. 23.

8 En el mismo sentido se manifiesta Porto Dapena 1999-2000, p. 133. 
Es preferible considerar que la entrada, el vocablo y el lema no son autónimos ni jeroglíficos de sí mismos, sino signos mencionados y no por un "metalenguaje", sino por el lenguaje de descripción de que hace uso la lexicografía, que solamente se diferencia de la lengua ordinaria por los artificios con que abstrae las palabras en vocablos y las condiciones morfológicas y sintácticas del vocablo en lemas. En conclusión, el lenguaje en el que se presenta la entrada, el vocablo y el lema es la propia lengua que toma por objeto el diccionario monolingüe. El acto proposicional comienza en su entrada por ser un acto referencial de carácter ostensivo (p. 129).

L. subraya el hecho de que no se trata de una simple cuestión terminológica: o la reflexión sobre el lenguaje es un hecho metalingüístico o es un hecho pragmático. La decisión no es ciertamente cuestión de palabras, hay implicaciones teóricas de un presumible largo alcance.

3.2. Lo que no me parece tan claro son las ventajas teóricas de la solución pragmática, ya que para evitar la homonimia entre el signo y su autónimo L. aumenta el número de unidades abstractas para poder dar cuenta del proceso de objetivación en que consiste el artículo lexicográfico.

Así, entre la palabra y la entrada se ve constreñido a situar el vocablo, que no deja de ser una unidad abstracta, social e históricamente constituida como forma canónica distinta de la entrada, la cual es a su vez el input del acto verbal de respuesta. En definitiva se llega también de este modo a un constructo teórico distinto de la palabra, caracterizado porque solo funciona como signo mencionado y no usado.

3.3. Efectivamente, se ha solucionado la cuestión del doblete entre el signo natural y su homónimo autónimo, pero se ha complicado, creo, la descripción del propio signo linguiístico al tener que aceptar una teoría del significado que prevea la suspensión del contenido léxico y de los rasgos morfosintácticos cuando el signo se menciona. La fórmula podría ser algo como por ejemplo esto:

$$
\text { /cantar/ = E + C + vocablo de cantar } 9 .
$$

$9 \quad E$ está por 'expresión' y $C$ por 'contenido'. 
En realidad, como el propio L. reconoce,

Puede uno preguntarse si la duplicidad de los signos en uso y a la vez en mención es más complicada para la teoría que la existencia de la duplicidad de léxicos entre la lengua y la metalengua (p. 128).

L. sostiene que no, pero lo cierto es que la mención (de palabras o de cualquier otra unidad o segmento del discurso) tiene consecuencias gramaticales ${ }^{10}$. No en vano, L. admite que este es precisamente el campo del análisis en el que "se produce alguna ganancia" (p. 127, n. 18), ya que explicaría algunos fenómenos morfológicos y sintácticos de la "mención".

3.4. Ciertamente si solo tuviésemos en cuenta el diccionario monolingüe habría que estar de acuerdo con L. en que la opción teórica de la autonimia es más costosa que la propuesta pragmática. Pero no podemos dejar de tener presente que:

a) Los diccionarios no son el único tipo de discurso en que se produce autonimia, o si se quiere, hay otros tipos de discurso en que los signos se mencionan; la mención no es solo del signo, se mencionan los significados, los significantes, una parte de los significantes, etc., es decir que no siempre el vocablo como forma canónica soluciona el problema de la mención.

b) Estos discursos metalingüísticos (o receptores de signos mencionados) comparten una serie de rasgos pero no son todos ellos susceptibles de la misma descripción pragmática. Esto es, entre un artículo lexicográfico y "su marido no me gusta" o "cantastes es vulgar" hay una sola cosa en común: el hecho de que la entrada del artículo en cuestión, marido y cantastes no son signos usados; en todos ellos se suspenden muchas de las propiedades que los caracterizan como elementos léxicos de una lengua. Ahora bien, si para la entrada lexicográfica se puede perfectamente admitir que se trata de una respuesta a la pregunta "¿qué significa x"?, si se puede, pues, proceder a una caracterización de esta res-

10 Cfr. Rey-Debove 1978; algunos puntos se discuten en Castillo Peña 1998. 
puesta como acto verbal socialmente pertinente, ¿Qué clase de acto verbal es el que explica cantastes? y, sobre todo, ¿ por qué cantastes es un sustantivo? Estas son las preguntas a las que intenta contestar la hipótesis de la autonimia, la cual, desde este punto de vista es más rentable, al acoger en una hipótesis unitaria un mayor número de fenómenos lingüísticos dispersos.

c) Al amparo de la diferencia entre metalengua de signo y metalengua de significado se han distinguido hechos notables que caracterizan al artículo lexicográfico como tal, hechos que la propuesta de lectura pragmática de L. no explica. Entre ellos merece, por su relevancia en la teoría (y en la práctica) lexicográfica sobre el español, un cierto detenimiento la llamada teoría del contorno.

Contorno es el término con que Manuel Seco (1987, pp. 35-45) traduce el concepto de entourage de la perífrasis definitoria. Con este se trata de distinguir en la definición aquellos elementos que no forman parte del significado, sino que son "elementos habituales del contexto" (p. 45) sintáctico en el que el signo habitualmente funciona.

El contorno es aquella parte de la definición que "sobra" cuando la perífrasis definitoria sustituye al definido; esta sustitución, quizá redundante en el lenguaje común, es, sin embargo, uno de los pilares de la práctica lexicográfica, ya que garantiza la "sinonimia" entre la "palabra" y su "definición": si talar es "cortar por el pie masas de árboles" es porque podemos sustituir esa definición en esta frase: "/han talado/ el bosque" > "/han cortado por el pie masas de árboles/ el bosque". En este ejemplo es evidente que lo sustituible es solo "cortar por el pie", y que "masas de árboles" es el contexto sintáctico exigido por talar en su perífrasis definitoria. De ahí la necesidad de distinguir ambos fenómenos en la definición. M. Seco propuso aislarlo con corchete, de forma que talar quedase definido así: "Cortar por el pie [masas de árboles]".

La teoría del contorno se ha convertido en práctica generalizada en la lexicografía contemporánea no académica del español y su soporte teórico es, precisamente, la diferencia entre metalengua de signo y metalengua de contenido. Si negamos legitimidad teórica al concepto de metalengua, habrá que explicar por qué "la lengua de descripción" usa- 
da por el diccionario es redundante. Pero, sobre todo habrá que asignar en la teoría del diccionario monolingüe un espacio a los diccionarios de autor y a sus particulares lenguajes de descripción, y habrá, por último que plantearse la auténtica relación que hay entre estos diccionarios de autor y el acto verbal de respuesta "socialmente pertinente". Es decir habrá que estudiar qué sucede con el concepto de autoridad cuando la colectividad dispone de más de una respuesta para cada pregunta, cuando la colectividad encuentra que no hay uno sino varios depósitos del léxico, y que en cada uno la respuesta se codifica de manera diferente.

4. El cuarto capítulo indaga en la naturaleza de la llamada "ecuación sémica" ", esto es, analiza el tipo de relación que se da entre el lema y la definición propiamente dicha. Como se sabe, esta relación ha preocupado a los teóricos de la lexicografía por dos motivos: a) es una relación escondida bajo el anonimato de un punto, b) la elección de los verbos significar, ser o llamarse (por citar solo algunos de los posibles verbos de lengua que pueden regir la predicación en que consistiría la definición) no es indiferente para el estatuto con que la definición se contemple en una teoría semántica o léxica.

4.1. El esqueleto de la reflexión de L. es la difundida idea de que la definición es equivalente al lema, es decir, que hay una relación sinonímica entre el vocablo definido y su perífrasis definitoria. Si el signo $\mathrm{X}$ es equivalente a la perífrasis Px $(X=P x)$, entonces, sostiene L., la equivalencia no se da entre signos, sino entre "los significados de esos signos, que son capaces de sustituirse mutuamente en cualquier enun-

11 Lara atribuye la denominación "ecuación sémica" a J. Rey-Debove 1971: "Josette Rey-Devobe (1971: 152) propuso llamar esa relación ecuación sémica" (p. 133). En realidad, ya en Rey-Devobe 1966 aparece el término, (precisamente en el título del trabajo), pero, me parece justo decirlo, la "ecuación" como metáfora para definir la relación que se establece entre definiens y definición se ve ya en Introducción a la lexicografía moderna de Julio Casares, cuya primera edición es de 1950: "Una definición verdaderamente lograda puede encerrar tanta belleza intelectual, al fin y al cabo se trata de una ecuación, como la resolución elegante de un difícil problema matemático" (p. 162). 
ciado que los contenga. De modo que la relación de sinonimia es una relación de equivalencia solo cuando se establece entre significados de signos" (p. 145). Por ello, tras discutir las dificultades de una ecuación sémica construida con ser, designar o llamarse, acepta como conclusión natural que dicha ecuación se establece gracias al soporte del verbo significar: botella significa 'vasija de cristal con el cuello angosto que sirve para contener líquidos'. Este argumento sirve a L. para criticar la ecuación sémica con ser propuesta por J. Rey-Debove (1989 y 1991) y, de paso, volver a negar la autonimia tanto de la entrada como de la perífrasis definitoria.

Me detendré en estos dos últimos puntos para volver después al problema general que arranca de la equivalencia entre definición y lema.

4.2. En lo que se refiere al verbo que establece la relación entre lema y definición creo que conviene matizar algunos aspectos, quizá menores, no considerados en el elegante análisis de L. En primer lugar, la cuestión histórica o, si se prefiere, genética: los primeros diccionarios monolingües españoles declaran explícitamente (aunque no siempre) el verbo que preside la predicación; la normalización progresiva (producto en no pocos casos de la necesidad práctica de ahorrar espacio) ha sido la primera causa a la que conviene atribuir la famosa "ambigüedad" del punto que separa lema y definición. En segundo lugar, creo que no se debe prescindir completamente de otra perspectiva de análisis: aquella que establece que lo que sigue al punto no es solo la definición, sino un enunciado del que esta es una parte y no el todo. Efectivamente para aceptar ser o significar como verbos que establecen la ecuación sémica L. solo tiene en cuenta la perífrasis definitoria; creo, sin embargo, que una teoría que explique adecuadamente la secuencia "Botella. Vasija de cristal con el cuello angosto que sirve para contener líquidos" no debe excluir el hecho de que lo que realmente se encuentra a disposición de la comunidad lingüística es "Botella. s.f. Vasija de cristal con el cuello angosto que sirve para contener líquidos"; ese "s.f." debe tener algún valor.

4.2.1. Para explicar este valor puede ser conveniente, como decía arriba, no perder de vista la historia del diccionario. En otros trabajos 
he insistido en la idea de que el diccionario es un producto histórico en un doble sentido: a) porque podemos verlo en su devenir a través de las distintas ediciones o de las influencias de un diccionario sobre otro y b) porque todo diccionario es portador en su macroestructura y microestructura de esa historia. Cuando se estudian las diferencias entre una edición y la sucesiva de un diccionario cualquiera se están tratando ambas ediciones como objetos independientes e individuales, como si fuesen dos diccionarios distintos; la idea del diccionario como producto histórico se refiere más bien al hecho de que es susceptible de un análisis diacrónico que vea cada artículo como una serie sucesiva de estratos organizados (o acumulados) en el tiempo.

Es cierto que una teoría del diccionario monolingüe no es un análisis de un diccionario cualquiera, por ello esta última observación no debe considerarse como crítica u objeción al trabajo de L., el cual no peca de omisión cuando evita el análisis histórico para establecer el verbo significar como fundamento de la predicación en que consiste la definición, pero tampoco se habría excedido en una reflexión que explicase cómo y por qué aparece el verbo ser en las definiciones de los primeros diccionarios. Tomaré como ejemplo el Diccionario de Autoridades. En este hay definiciones "modernas", esto es construidas sin verbo (1), junto a definiciones con ser (2), significar (3), valer tanto como (4), llamarse (5), entenderse (6), dar (7), etc.:

(1) Alumbrar. V. a. Dar luz y claridad; claridad propia del Sol, de la Luna y de las Estrellas, y en la tierra del fuego, y de las cosas compuestas de él, y de la materia combustible.

(2) Alumbrar. Metaphoricamente es también conceder parto feliz a una muger para que de a luz la criatura sana y con felicidad. Esta voz solo se usa respecto de Dios, que es quien únicamente puede hacer este beneficio: y así comúnmente se saluda a las preñadas diciéndolas (sic) Dios la alumbre con bien.

(3) Alumbrar. Significa también desahogar, desembarazar la vid, o cepa de la tierra, que se le había arrimado para abrigarla. Es voz de la Agricultura y con propiedad se dice de las viñas recién plantadas para que el podador vea la vid y la reconozca, y por esto se dixo Alumbrar. 
(4) Alumbrar. Metafóricamente vale tanto como ilustrar, enseñar y hacer patente y claro a otros lo que ignoraban, dudaban, o no alcanzaban.

(5) Altura. En la Geometría se llama la perpendicular tirada desde el vértice de la figura hasta su base.

(6) Altura, o Alturas. Se entienden las cumbres de los montes, sierras, collados y parages altos del campo.

(7) Alubias. Nombre que se da en algunas partes, como es en la Mancha y Reino de Murcia, a la legumbre o planta que comúnmente se llama en Castellano judías, judigüelos, frijoles y majocas, y habichuelas en Andalucía.

Como puede verse en esta breve cala el primer diccionario académico no se decide por un tipo de predicación ${ }^{12}$. Ahora bien, lo que interesa aquí no es tanto el análisis de esta "primitiva" tipología como el hecho de que a) en todos los casos, con verbo o sin él hay punto entre el vocablo y la definición (es norma en todo el Diccionario) y b) los predicados referidos al signo y no al significado prefieren ser ("es voz"). Se podría concluir en primer lugar que la naturaleza de la predicación es en los orígenes de la lexicografía monolingüe moderna independiente de la definición propiamente dicha. Cuando estos enunciados fueron sometidos a restricciones (debidas, ciertamente, a cuestiones muy alejadas de una teoría sobre el signo) los verbos desaparecieron y su predicado quedó como único exponente del discurso lexicográfico. Por otra parte, el único dato constante es que, no obstante la heterogeneidad vista, el verbo que predica de todo el signo es ser.

4.2.2. Efectivamente, a mi juicio, descartar ser como cópula entre el sujeto-lema y el predicado-definición del enunciado lexicográfico impide considerar las "otras informaciones" que se dan en el artículo como parte del enunciado lexicográfico. Como decía arriba (cf. 4.2.) las

12 Faltan estudios de este tipo sobre el Diccionario de Autoridades, por lo que no me atrevo a decir que son tipos de predicación sinónimos, equivalentes, o que cada tipo de predicación se pueda deber a un redactor distinto o a alguna clase de criterio, que, por el momento, desconozco. 
marcas gramaticales, diatópicas, diacrónicas, etc. son también parte del enunciado. Este convencimiento me lleva a proponer si no sería más interesante para una teoría del diccionario entender que la paráfrasis más adecuada de "Botella. s.f. Vasija..." es "Botella es un nombre femenino que significa vasija ...".

4.2.3. El grave inconveniente de esta propuesta (que solo en parte está en desacuerdo con L.) consiste en que me obliga a revisar la cuestión de la equivalencia (cfr. arriba 4.1.).

Volveré a examinar rápidamente el problema:

a) Se afirma que Botella (A) = "Vasija de cristal con el cuello angosto que sirve para contener líquidos" (B); (ecuación sémica: $\mathrm{A}=\mathrm{B})$.

b) Para que la igualdad tenga sentido los dos términos que la establecen deben ser equivalentes.

c) Se afirma que la equivalencia debe ser semántica y sintáctica; esto es A y B deben ser sinónimos y si A es un sustantivo, B debe ser un sustantivo o un sintagma nominal, si A es un verbo, B debe ser un verbo o un sintagma verbal, etc.

d) Esta equivalencia implica que la perífrasis definitoria pueda sustituir al lema en cualquier secuencia de habla.

Aparentemente, la hipótesis es correcta, puesto que la primera afirmación (a) es el axioma que consiente la función del diccionario y las otras tres (b, c y d) son, cada una, consecuencia directa de la que le precede. Pero solo en apariencia, porque la última de las afirmaciones no es ni necesaria para una teoría lexicográfica, ni comprobable. Intentaré justificar por qué:

En primer lugar, es imposible aceptar a priori que la definición de botella podrá sustituir a botella en todos los contextos posibles porque estos son infinitos.

En segundo lugar, está demostrado que dicha sustitución es solo parcialmente posible en el caso de los sustantivos; las definiciones de ver- 
bos, adjetivos y adverbios plantean muchísimos problemas ${ }^{13}$. No parece adecuado que un principio ordenador, presuntamente fundamental para la comprensión y justificación de la naturaleza de la definición, tenga tantas excepciones (a no ser que se elabore, con otros criterios, una teoría de la definición de los adjetivos, otra para los adverbios, y otra, distinta, para los verbos).

En tercer lugar, la sustitución de una definición por su vocablo correspondiente en una secuencia de habla es una manipulación artificiosa de las posibilidades del sistema lingüístico; si se admite que la definición es un discurso metalingüístico se notará con facilidad las dificultades teóricas que plantea la inserción de un discurso metalingüístico en un fragmento de habla cualquiera, ya que lo que ocurre es que dicho discurso deja de ser metalingüístico, deja de ser el predicado de una frase para convertirse, formalmente invariado, en otra cosa: "La vasija de cristal con el cuello angosto que sirve para contener líquidos se ha roto", aunque posible y correcta, no es equivalente en el habla a "La botella se ha roto", aunque ambas sean correferenciales. Las dos frases no son equivalentes, o, mejor dicho, botella no es equivalente a vasija de cristal con el cuello angosto que sirve para contener líquidos en esos fragmentos de habla: la referencia, la determinación y la deixis apuntan a mundos significados distintos.

Ahora bien, L. rechaza que la definición sea un enunciado metalingüístico; el argumento que he utilizado se basa precisamente en esta caracterización, de forma que convendrá aportar otro tipo de razonamiento.

Aun aceptando que la definición sea un discurso lingüístico igual

13 Cfr. Porto Dapena 1988; en este trabajo se puede ver un planteamiento crítico general a la teoría del contorno y a la posibilidad de conmutación entre definición y término definido; entre otros casos dice por ejemplo Porto Dapena que cuando las definiciones de los adjetivos son oraciones de relativo, nunca podrán ser sustituidas en un predicado nominal: "Simpático. Que inspira simpatía" > * Mi amiga es que inspira simpatía", ya que "la identidad de contenido no supone identidad de comportamiento sintáctico y, aun en el caso de que se dé esta última, pueden existir restricciones contextuales, de manera que la sustitución sea posible en ciertos contextos, pero no en otros" (p. 137). 
a cualquier otro, habrá que convenir en que es, al menos, un tipo de discurso distinto. L. lo caracteriza pragmáticamente como un acto verbal de respuesta. Imagino que la diferencia entre la respuesta “¿Qué significa x?" y la que se obtiene preguntando "¿Qué enfermedad tengo?" no solo radica en la diversidad de los mundos referenciales aludidos (el del significado de las palabras y el de las enfermedades); quiero decir que algunos aspectos del sistema lingüístico como los modelos con que se construyen los discursos, o las variedades diafásicas, deberían tener algo que ver en el tipo de respuesta: un profesor de lengua o un médico responderán a ambas preguntas de forma diferente a como lo haría un hablante cualquiera. Pues bien, imagino que la inadecuación pragmática que se puede producir en un discurso si se insertan variedades diafásicas o diastráticas distintas debe tener algo en común con la inadecuación que se observa cuando se realizan en un discurso esas a mi juicio artificiosas operaciones sustitutivas entre lema y definición. En todo caso, en ausencia de una explicación por parte de L. de este concreto problema, el argumento precedente solo intenta defender, con lo que imagino puedan ser criterios aceptables para el propio L., una hipótesis que rechace la equivalencia (o al menos la ponga en duda) como cuestión fundamental para la comprensión teórica del fenómeno lingüístico en que consiste la definición. Personalmente me parece más elegante el argumento utilizado en el párrafo anterior, aunque para ello haya que aceptar la hipótesis de la autonimia.

5. El análisis semántico de la definición que lleva a cabo L. en el quinto capítulo le conduce, en perfecta coherencia con la línea por él trazada, a afirmar que:

a) La definición lexicográfica no es una descripción del significado, sino su "reconstrucción". Reconstrucción que el lexicógrafo lleva a cabo abstrayendo los datos mediante una "elaboración constructiva que pretende alcanzar el nivel de generalidad y de precisión en que el significado del vocablo garantiza la inteligibilidad social" (p. 230). 
b) La definición lexicográfica es un fenómeno cultural ${ }^{14}$, ya que al proceso de reconstrucción del significado, guiado por la abstracción crítica de los datos obtenidos del análisis de manifestaciones lingüísticas concretas, se incorporan tanto los valores sociales que una comunidad asigna a un fenómeno significante como el propio conocimiento científico de ese fenómeno.

5.1. No aborda L. la problemática de la tipología de la definición, ni la de la forma que esta deba tener para conseguir sus fines; el autor se ocupa de justificar la naturaleza pragmática, y por ello social, de la definición. En realidad se deduce que el establecimiento de una tipología de la definición es preocupación de la "filosofía en general" (p. 169) o de los tratados sobre técnica o metodología lexicográfica -tal y como se apuntaba en la introducción.

Tampoco forma parte de la discusión la consecuencia que pueda tener sobre la "memoria social del léxico" el hecho de que a) una definición pueda ser sometida a crítica, y b) una definición pueda ser rechazada (por la comunidad lingüística o por la comunidad científica). La relación entre la forma que una definición puede tener y los hechos apenas apuntados se suspende ante la decisión de L. de tratar al diccionario como un ente teórico no necesariamente identificable con un objeto particular. Efectivamente, que haya una relación entre el tipo de definición y la categoría gramatical del vocablo, es solo un problema que afecta a la técnica con la que un diccionario concreto haya sido elaborado; que una definición, por ser hiperonímica, sinonímica o relacional, no defina solo es posible en un diccionario concreto; que una definición sea, en realidad, la suma de las definiciones que se dan bajo la forma de "acepciones" solo es atribuible a la decisión concreta de un lexicógrafo determinado en un diccionario dado. Lo que no parece tan obvio es que problemas de tal naturaleza no formen parte de la teoría del diccionario.

Queda también sin discusión en el trabajo de L. la compleja relación

14 En un sentido parecido al de Rey 1987a y 1987b. 
entre la reconstrucción del significado y el uso que el lingüista hace o puede hacer de esa reconstrucción; uso que, no olvidemos, es necesariamente dependiente de la estructura formal de las definiciones ${ }^{15}$ y que algún peso debería tener en una teoría del diccionario.

6. El último capítulo es un brillante pero rápido repaso del concepto de normatividad aplicado al diccionario como depósito de la memoria social del léxico. A este propósito, distingue L. dos cuestiones no siempre bien entendidas en la lexicografía hispánica: la normatividad como "selección de posibilidades" o "normatividad débil" (p. 236) y la "imposición de posibilidades" que "orienta la memoria del léxico cultivado, seleccionando su composición, restringiendo sus posibilidades e imponiendo una concepción de la lengua histórica a la comunidad lingüística" (p. 257). Esta distinción teórica se ve apoyada por las diferencias que a efectos normativos hay entre la representación gráfica y la transcripción fonética, y entre los diferentes tipos de marcas, con las siguientes conclusiones: a) La transcripción fonológica impone la descripción de una variante sobre las otras en una lengua dada (p. ej., en español la transcripción con / $\theta /$ o con /s/; b) en cambio, la escritura "es un hecho gráfico que no revela su origen normativo mientras no se presente algún caso de inestabilidad ortográfica" (p. 247); c) la nomenclatura es un catálogo de vocablos "aceptados" por lo que tiene un fuerte "cuño normativo"; d) las marcas diatópicas tienden hoy día a perder valor normativo y a ganar valor descriptivo; e) las marcas diafásicas y diastráticas carecen de valor teórico empíricamente demostrable por lo que deben ser consideradas como una "evaluación embozada del uso social por parte del lexicógrafo" (p. 251); por último, f) las marcas terminológicas carecen de valor normativo.

15 Me refiero al espinoso problema de la consideración teórica que merecen los elementos que constituyen una definición: sememas, semas, rasgos sémicos, rasgos distintivos, sustancia del contenido, forma del contenido, etc. son atributos que frecuentemente se aplican a las unidades del discurso definitorio. De ahí la homologación entre definición sinonímica y sinónimos, o la identificación entre la primera palabra de la perífrasis definitoria de un lema y el hiperónimo del lexema correspondiente. A este respecto cfr. Castillo Peña 1992, pp. 508-525 y 1993, pp. 133-151. 
Esta veloz discusión parece apuntar a que, en su conjunto, el diccionario manifiesta una normatividad del segundo tipo, ya que a) las decisiones en cuanto a la ortografía son constantes (dejando de lado la cuestión histórica, al menos en español), porque constante es la incorporación de neologismos y de préstamos; b) solo la nomenclatura de un diccionario histórico es verdaderamente "descriptiva" o "normativamente débil", ya que únicamente el diccionario histórico aspira a recoger todo el léxico de una lengua; por otra parte, no se menciona el delicado problema de la relación entre el diccionario y el sistema ${ }^{16}$ : el complicado equilibrio entre la productividad derivacional y la lematización ${ }^{17}$; c) la "marca cero" (o ausencia de marca) -aspecto no tratado por L. - tiene impronta normativa cuando hay otras marcas, lo cual implica que solo un diccionario sin marcas diatópicas, diafásicas y diastráticas puede ser caracterizado como "normativamente débil".

Se cierra así un trabajo teórico de notable solidez y exquisita coherencia, raro en el ámbito de la lexicografía hispánica, más concentrada en la descripción de lo particular que en la teorización de lo general (y esta es una de las grandes virtudes de este libro, aunque en algunas ocasiones, como he tenido ocasión de apuntar, el objeto teórico sea tan abstracto que una mayor reflexión sobre lo particular se eche de menos). Su tesis central -la naturaleza social del diccionario- está, como se ha ido viendo, irreprochablemente construida, hasta el punto de que lo discutible radica, en mi opinión, en algunos de sus argumentos (precisamente aquellos en los que me he detenido), aunque su crítica o revisión no implica, a mi juicio, el tambaleo del edificio, el cual, en todo caso resiste con una envidiable estabilidad.

16 Aludo a la diferencia entre sistema y norma tal y como la entiende Coseriu 1967.

17 Cfr., por ejemplo, Pena 1994-1995. 


\section{BIBLIOGRAFÍA}

Ahumada LARA, Ignacio (1987): Aspectos de Lexicografía teórica, Granada, Universidad de Granada.

Alvar EzQuerra, Manuel (1993): Lexicografía descriptiva, Barcelona, Biblograf.

BüHLER, Karl (1967): Teoría del lenguaje, Madrid, Revista de Occidente. CASARES, Julio (1950): Introducción a la lexicografía moderna, Madrid, CSIC (cito por la $3^{\text {a }}$ reimp.de 1992).

Castillo PeÑa, Carmen (1992): "La definición sinonímica y los círculos viciosos", BRAE, LXXII, pp. 463-566.

— (1993): "La definición sinonímica y los círculos viciosos", BRAE, LXXIII, pp. 133-213

_ (1998): "Función metalingüística, metalenguaje y autonimia", Lexis, XXII, 2, pp. 243-266.

COSERIU, Eugenio (1967): "Sistema, norma y habla", en Teoría del lenguaje y lingüística general, Madrid, Gredos, pp. 11-113.

HABERMAS, Jürgen (1987): Teoría de la acción comunicativa, Madrid, Taurus.

LARA, Luis Fernando (1989): "Une critique du concept de métalangage", Folia linguistica, 23, 3-4, pp. 387-404

(1990): Dimensiones de la lexicografía, México, El Colegio de México.

— (1997): Teoría del diccionario monolingüe, México, El Colegio de México.

PENA, Jesús (1994-1995): “Formación de palabras, gramática y diccionario", Revista de Lexicografía, I, pp. 163-180.

Porto DAPenA, José-Álvaro (1988): "Notas lexicográficas: La información sintáctica en los diccionarios comunes”, LEA, X, 1, pp. 133151.

_ (1999-2000), "Metalenguaje y lexicografía", Revista de Lexicografía, VI, pp. 127-151.

QUEMADA, Bernard (1987): "Notes sur lexicographie et dictionnairique", Cahiers de Lexicologie, 51, pp. 229-242.

REY, Alain (1987a): "Le dictionnaire culturel”, Lexicographica, 3, pp. 350.

_ (1987b): "La notion de dictionnaire culturel et ses applications", Cahiers de Lexicologie, LI, pp. 243-256.

ReY-Devobe, Josette (1966): "La définition lexicografique: recherches sur 
l'équation sémique", Cahiers de Lexicologie, VIII, 1966-1, pp. 7194.

—_ (1971): Etude linguistique et sémiotique des dictionnaires français contemporains, Mouton, La Haya.

— (1978): Le métalangage, Le Robert, Paris.

— (1989): "Prototypes et définitions", DRALV, 41, pp. 143-167.

_ (1991): "L'objet référentiel du lexique", Colloque de sémiotique de Perpignan, (apud Lara 1997).

SEARLE, John (1980): Actos de habla, Madrid, Cátedra.

SECO, Manuel (1987): "El contorno en la definición", en Estudios de lexicografía española, Madrid, Paraninfo, pp. 35-45. 